\title{
Conceptualizing the integration of HIV treatment and prevention: findings from a process evaluation of a community-based, national capacity-building intervention
}

\author{
Eric Mykhalovskiy ${ }^{1}$, San Patten ${ }^{2}$, Chris Sanders ${ }^{1}$, Michael Bailey ${ }^{3}$ and Darien Taylor ${ }^{3}$ \\ ${ }^{1}$ Sociology, York University, Toronto, Canada \\ 2 Sociology, Mount Allison University, Sackville, Canada \\ ${ }^{3}$ Canadian AIDS Treatment Information Exchange, Toronto, Canada
}

Submitted: 25 June 2008; revised: 07 November 2008; accepted: 15 January 2009

Published online first: 25 February 2009

Abstract

Objective: This paper responds to a gap in knowledge about the conceptualization of integration in community-based AIDS organizations (CBAOs)

Methods: A community-based process evaluation was conducted of a national intervention, developed by the Canadian AIDS Treatment Information Exchange (CATIE), to enhance treatment information provision in $\mathrm{CBAOs}$ and encourage its integration with prevention services. Our study involved 13 interviews with intervention participants in 6 CBAOs across Canada, CATIE staff, and funders, as well as a 25 -person verification exercise.

Results: Intervention participants conceptualized integration as linking front-line HIV treatment, health promotion and prevention services, emphasizing mediation between scientific and lay knowledge, the political context of integration and the role of social determinants in clients' health and access to services. Challenges to integration include high staff turnover and inflexible funding structures. Complex health education related to the relationship between viral load and HIV transmission is a critical area of integrated service delivery.

Conclusion: Study findings help distinguish a community-based concept of HIV-related integration from alternative uses of the term while pointing out key tensions associated with efforts to integrate HIV prevention and treatment in a community-based context.

Keywords: HIV - Treatment information - Prevention - Community organizations - Integration.

\section{Introduction}

Current thinking on HIV pandemic management emphasizes integrating the two primary responses to HIV, preventing transmission and treating those infected with the virus. ${ }^{1,2}$ Historically, at the level of population-based response, HIV prevention and treatment have been counterposed, treated as mutually exclusive or pursued as programmatic silos. ${ }^{3,4}$ Three developments have fundamentally challenged this disconnect between prevention and treatment. First, increased global availability of antiretroviral therapy (ART) has made HIV treatment a viable option in a number of developing countries. ${ }^{5}$ Second, global responses to the pandemic show that neither treatment nor prevention alone can successfully halt HIV. ${ }^{3,6}$ Third, clinical studies indicate that by lowering the amount of HIV in the blood, ART can reduce the risk of transmitting HIV. ${ }^{7-9}$ Once considered exclusively a clinical resource for improving the health of people living with HIV (PLHIV), ART is now routinely referred to as a prevention tool and proposals to use treatments for prevention purposes at a population level are being widely popularized. ${ }^{10,11}$ Integrating HIV treatment and prevention holds implications for all those working in the HIV field as well as for PLHIV and those at risk of HIV. Most published research on integration addresses national and global policy issues ${ }^{1,3-5}$ or epidemiological forecasts about using ART for HIV prevention. ${ }^{10,11}$ Other research explores integrating prevention with community-based models of treatment provision in developing countries. ${ }^{12,13}$ Very little has been written about the implications of integration for the global North, with particularly little attention paid to the issues arising for community-based AIDS 
Table 1. Sample curriculum for capacity-building intervention - Alberta site.

\begin{tabular}{|c|c|}
\hline Day 1 & Topic \\
\hline 9:00-9:30 & Introductions \\
\hline 9:30-10:15 & $\begin{array}{l}\text { An integrated HIV treatment information model } \\
\text { - publications and services as resources }\end{array}$ \\
\hline 10:30-12:00 & $\begin{array}{l}\text { Highly Active Anti-Retroviral Therapies } \\
\text { - Review of viral replication } \\
\text { - Drug classes } \\
\text { - What's in the pipeline }\end{array}$ \\
\hline $1: 00-2: 00$ & HIV co-infection with HCV \\
\hline $2: 30-4: 00$ & $\begin{array}{l}\text { HIV treatment strategies } \\
\text { - Starting therapy } \\
\text { - Adherence } \\
\text { - Resistance } \\
\text { - Interrupting therapy }\end{array}$ \\
\hline 4:00 & Talking circle \\
\hline Day 2 & Topic \\
\hline 9:00-10:30 & $\begin{array}{l}\text { HIV from an Aboriginal health and wellness } \\
\text { perspective }\end{array}$ \\
\hline 10:45-12:00 & $\begin{array}{l}\text { Complementary/alternative therapies } \\
\text { - Overview } \\
\text { - Cautions } \\
\text { - How to research natural products }\end{array}$ \\
\hline $1: 00-2: 00$ & $\begin{array}{l}\text { Coping with side effects } \\
\text { - A holistic approach }\end{array}$ \\
\hline $2: 15-3: 30$ & $\begin{array}{l}\text { Integration exercise } \\
\text { - How can you use HIV treatment information in your } \\
\text { work? }\end{array}$ \\
\hline $3: 30-4: 00$ & Talking circle \\
\hline
\end{tabular}

organizations (CBAOs). ${ }^{14}$ Yet these organizations are often front-line points of contact and key sources of support for preventing HIV transmission and for helping PLHIV make treatment decisions. ${ }^{15,16}$ This paper responds to this gap in knowledge by exploring the response to integration of one national non-governmental organization, the Canadian AIDS Treatment Information Exchange (CATIE).

\section{The intervention}

CATIE was established in Toronto in 1990. Until recently, its mandate was to produce and distribute "accessible, accurate, unbiased and timely" treatment information to PLHIV "and the people and organizations that support them.."17 In 2008, reflecting the growing emphasis on integration, CATIE's mandate was expanded with Public Health Agency of Canada (PHAC) funding to include the exchange of prevention information. CATIE currently provides a range of services including a 1-800 treatment inquiry hotline, a host of print and web-based publications, educational workshops, and a library service.
CATIE was established to empower PLHIV through enhanced treatment education and information. At the time it was founded, most CBAOs in Canada were focused on prevention education, counseling and practical assistance; few were actively providing HIV-related treatment information. While this situation has changed,$^{18}$ treatment information and education remain underdeveloped relative to prevention services amongst Canadian CBAOs.

In 2004, CATIE launched the "Integrating HIV/AIDS Treatment Information, Prevention and Support Services Capacity Building Project." The intervention responded to the call for integration by seeking to enhance the organizational presence of treatment information services in Canadian CBAOs and by helping CBAOs strike a balance between treatment and prevention in their service profiles. It targeted small CBAOs with limited treatment information resources that are located outside of urban areas.

The intervention provided tailored workshops to local staff and volunteers of participating CBAOs that followed an assessment of their treatment information literacy, capacity building needs and available resources. Table 1 suggests content typical of the workshops. Overall, the goal of the intervention was to enhance local CBAO capacity to provide health education to individual clients, to encourage integration and to link participants with CATIE in ongoing networks of treatment information sharing and support.

\section{Methods}

The study combined elements of community-based research (CBR) and process evaluation. CBR has been widely used in studies of HIV/AIDS where it has been developed in tension with the power relations associated with positivist methods of research. CBR seeks to create a knowledge for, not of, PLHIV. It addresses research questions that are of concern to PLHIV and community organizations that serve them, formulates inquiry to explore everyday experiences, involves community members in the research process, and generates applied findings that can be used in community settings. ${ }^{19-21}$

Process evaluation has emerged as a popular, if heterogeneous, form of research in health care. ${ }^{22,23}$ Our approach is based on an important distinction between the evaluation of outcomes and the evaluation of organizational processes, first articulated in industrial research and later generalized to health care. ${ }^{24}$ Accordingly, this study does not report on the evaluation of outcomes. Outcome evaluation for the intervention was conducted locally, with each participating CBAO setting its own objectives and measuring its own achievement of outcomes depending upon their specific needs for capacity-building. 
Table 2. Profiles of organizations participating in capacity-building intervention.

\begin{tabular}{|c|c|c|}
\hline Organization / Information & Mission / Mandate Statement & Primary Services \\
\hline $\begin{array}{l}\text { AIDS Coalition of } \\
\text { Nova Scotia } \\
8 \text { staff, Est. } 1995 \\
\text { Halifax, Nova Scotia }\end{array}$ & $\begin{array}{l}\text { Empower PLHIV through health promotion and } \\
\text { support, and reduce the spread of HIV in Nova Scotia }\end{array}$ & $\begin{array}{l}\text { An information resource centre and health } \\
\text { promotion services for PLHIV, an anonymous HIV } \\
\text { testing clinic }\end{array}$ \\
\hline $\begin{array}{l}\text { Bruce House } \\
9.5 \text { staff, Est. } 1988 \\
\text { Ottawa, Ontario }\end{array}$ & $\begin{array}{l}\text { Provide housing, care and support for PLHIV based } \\
\text { on the belief that everyone has the right to live } \\
\text { and die with dignity }\end{array}$ & $\begin{array}{l}\text { 24-hour care and support Transition House for } \\
\text { PLHIV requiring extensive physical and/or } \\
\text { psychosocial assistance }\end{array}$ \\
\hline $\begin{array}{l}\text { Pauktuutit Inuit Women } \\
\text { of Canada } \\
10 \text { staff, Est. } 1984 \\
\text { Ottawa, Ontario }\end{array}$ & $\begin{array}{l}\text { Assist and support the social, cultural, political and } \\
\text { economic betterment of Canadian Inuit women, } \\
\text { families \& communities }\end{array}$ & $\begin{array}{l}\text { Address abuse, diabetes, childhood development, } \\
\text { fetal alcohol syndrome, gender equity, teen } \\
\text { pregnancy, tobacco use, sexual health, and youth } \\
\text { rights }\end{array}$ \\
\hline $\begin{array}{l}\text { AIDS Program South } \\
\text { Saskatchewan (APSS) } \\
6 \text { staff, Est. } 1987 \\
\text { Regina, Saskatchewan }\end{array}$ & $\begin{array}{l}\text { Support community health and well-being } \\
\text { through sharing HIVIAIDS information resources }\end{array}$ & $\begin{array}{l}\text { Education and information, harm reduction, } \\
\text { community development and training, PLHIV } \\
\text { socioeconomic assistance, and life skills } \\
\text { development }\end{array}$ \\
\hline $\begin{array}{l}\text { HIV Edmonton } \\
10 \text { staff, Est. } 1987 \text { Edmonton, } \\
\text { Alberta }\end{array}$ & $\begin{array}{l}\text { Work with those infected with, affected by and } \\
\text { at risk of HIV; we work collaboratively to provide } \\
\text { education, support and advocacy }\end{array}$ & $\begin{array}{l}\text { Capacity building and community development, } \\
\text { PLHIV care and support, advocacy, public awareness } \\
\text { raising }\end{array}$ \\
\hline $\begin{array}{l}\text { Positive Living North } \\
12 \text { staff, Est. } 1992 \\
\text { Prince George, } \\
\text { British Columbia }\end{array}$ & $\begin{array}{l}\text { Help Aboriginal people achieve mental, spiritual, } \\
\text { physical balance in strong communities with full } \\
\text { access to the determinants of health }\end{array}$ & $\begin{array}{l}\text { PLHIV services \& training, prevention education for } \\
\text { the larger community and specific populations, } \\
\text { and Cultural Drop-in Centre for Aboriginal Peoples }\end{array}$ \\
\hline
\end{tabular}

Instead, the study focused on process issues related to the design and implementation of the intervention. Because the intervention is in its early stages and because it is organized around the introduction of a novel concept to communitybased work, our research focused on how study participants experienced the concept of integration. The central goal was to develop a more robust understanding of how integration was understood by key actors involved in the intervention, with an emphasis on the perspectives of front-line workers engaged in the practical realities of delivering services.

House has recently called for heightened reflexivity on the part of evaluation researchers with respect to the political context and value-based nature of their research. ${ }^{25}$ His concerns arise out of a US context where political pressures have constrained the methodological choices available to evaluators and promoted narrow conceptions of "scientific" research. We note, in this respect, that HIV evaluation research in Canada has yet to be generally constrained by the privileging of randomized control trials and numerically-based outcomes measurement that characterizes the US case. This study is situated within a political commitment to resist such a possibility, arguing that valuable program knowledge can be produced through alternatives to outcomes assessment. The alternative pursued here involves qualitative methods that privilege involvement and open expression by "those most concerned about the program" 25 on key process issues, including the expression of views that may be contrary to program or funders' goals. To ensure the possibilities of such communication, the interviews for this research were conducted by team members with no formal connection to CATIE.

\section{Data collection and analysis}

The study received ethics approval from York University and was conducted in 2006-7. The multi-method qualitative approach included individual interviews as the main source of data as well as analysis of key policy documents ${ }^{26-28}$ and a feedback session to elicit responses to a draft of the analysis. The feedback session was informed by procedures for validation developed by Smith ${ }^{29}$ and included 25 PLHIV and other representatives from 15 CBAOs from across Canada.

Semi-structured interviews ${ }^{30}$ were organized around a series of previously determined topics and focused on respondents' conceptual practices, work activities, and understandings of integration, particularly as experienced through the intervention. A total of 13 interviews were conducted with six representatives out of the seven intervention sites (one was lost due to staff changes), five CATIE staff and two PHAC representatives. Workshop participants represented CBAOs from regions across the country. For organizational profiles see Table 2. Interviews lasted from 30 to 90 minutes, were tape-recorded and transcribed. The second author conducted telephone interviews with workshop participants; the first author conducted all remaining interviews in-person. 
Analysis was conducted as an ongoing and iterative process beginning with data collection and continuing throughout the duration of the study. ${ }^{31}$ Transcripts were analyzed by the first three authors in face-to-face meetings. They were handcoded to identify sections of text dealing with participants' conceptualizations of integration, challenges in delivering the intervention and suggestions for improvement. These sections were compared and contrasted with respect to content and narrative in order to develop an analysis sensitive to respondents' meanings and perspectives.

\section{Results}

\section{Conceptualizing integration}

While study respondents generally spoke about integration in terms that emphasized the complementarity of HIV prevention and treatment, there were important differences in their understandings of the concept.

Funders generally privileged the goal of prevention, describing how treatment can enhance efforts to curb HIV transmission. One funder spoke about the preventive benefits of early diagnosis for HIV treatment, emphasizing the promotion of "healthy sexuality" and the engagement of PLHIV in HIV prevention work:

I mean if you can get people to access treatment, there may be benefits in terms of viral load. I also think there's a lot to treatment in terms of...helping [PLHIV] be healthy. And expanding it from just sort of being healthy disease-wise to being healthier in terms of their own life and that includes healthy sexuality... From a public health perspective if you're looking at targeting efforts to reduce the transmission of HIV, well who better to work with than people living with HIV.

Funders referred to "an integration policy direction" that was "sprinkled" throughout various guiding policies including the Federal Initiative to Address HIV/AIDS in Canada. The major impetus for integration was explained in terms of PHA longevity due to ART that increased opportunities for engaging in risk behaviours:

The rationale for where [integration] really comes from stems back to when the treatments were starting to come out... And there was concern and recognition that... the number of people living with HIV will be increased because they won't be dying at the same rate that they were before. So there'll be more people liv- ing with HIV and there will be more opportunities to engage in sex.

CATIE staff also understood integration in terms of how prevention and treatment can support one another. However, they were less inclined to privilege the goal of preventing HIV transmission and emphasized integration as an opportunity to enhance health promotion services for PLHIV:

I think there are ways that treatment has an impact on prevention and that would be like microbicides that are a prevention technology or, you know, positive prevention campaigns and the work that people with HIV can do in prevention campaigns... But I'm not really that interested in that. I'm still like... 'all you guys out there doing HIV prevention and education work need to know some basic stuff about treatment in order to serve people with HIV well'.

At the same time, CATIE staff spoke about the delicate balance between prevention and treatment, recognizing the vulnerability of treatment information services directed at PLHIV. One concern was that integration may distract CATIE from its traditional emphasis on treatment:

When CATIE was first formed there was explicit thinking that prevention should not be part of CATIE's mandate, that if CATIE took on prevention it would suck up this whole idea of a treatment information service... And other organizations felt very territorial about this, like, 'CATIE doesn't do prevention.' ...And we're an organization for people living with HIV, and that's who we want to serve and prevention can take you very far away from that.

Few intervention participants reported having used the concept of integration in their day-to-day work prior to the intervention. For many, the capacity-building workshop provided an opportunity to develop a way of thinking about a concept that in the end had practical relevance and resonance with their work experiences. As one participant put it:

We never called it integration before this project, we didn't understand it that way. Now we have an idea of what that word means, and we understand the value.

Intervention participants developed a basic, shared understanding of integration that emphasized the practical exigencies of day-to-day service provision. Through the intervention, they came to speak about integration through a language 
of practice focused on how to better link treatment and prevention services in their work to meet clients' needs:

Integration means providing treatment information, while also providing support, finding a house, emotional or trauma issues, bring[ing] up treatment issues at the same time so that [clients] don't have to go to many different places to find information.

For me, treatment integration means that anything to do with HIV programming, whether it be prevention, education, care, support, all these areas overlap and we have not always provided services with that understanding.

When discussing integrated service delivery, intervention participants drew on expansive notions of prevention and treatment. They included within the latter biomedical and alternative health information as well as culturally-specific ways of knowing health. They also noted that central to integration is translating scientific information about prevention and treatment into terms that respond to the values and practical exigencies faced by individual clients:

We're seeing more people come out now for support services. We have a needle exchange program, we're slowly building trust. If a client came in here for needle exchange, and they may mention that they just found out their HIV diagnosis, we give them the full information that they need even if they are using [such as] what the drugs might do in interaction with street drugs, do they feel safe to attend meetings with the doctor. I attend their appointments with them, help them comprehend the complex big words, break it down to the basics.

A particular concern noted by intervention participants was the challenge of providing health education on the topic of the relationship between ART, decreased viral load, and the risk of HIV transmission. They noted a high demand for such forms of integrated information. Some, such as the individual quoted below, felt comfortable providing health education on the use of ART as a prevention tool:

I tell folks that providing treatment can reduce the chance of transmission, it's a message that I'm fairly comfortable providing to clients, along with other information on how to prevent transmitting the disease. But we don't say it's clear-cut, that transmission is impossible, but that it lessens the possibility... It's important in providing services to PLHIV or HIV-negative people to always be very honest, not fear monger or perpetuate things that haven't been proven.

Other study participants, particularly those who took part in our feedback session, felt less at ease dealing with such information. Expressing concerns about the uncertain state of scientific evidence about viral load and HIV transmission and the potential for such information to encourage high risk behaviours, they urged CATIE to generate further resources on this topic and to better incorporate it into the intervention. Intervention participants also framed integration in relation to the broad social context of their clients' lives. Some used the language of holism to refer to how integration held promise for aligning services with the diverse needs of PLHIV and other clients that often traverse organizational distinctions between prevention and treatment. One participant noted how an approach to integration addressing broad contextual factors can harmonize prevention and treatment goals, helping PLHIV reduce transmission while at the same time improving their overall health:

I would like it to go in a different direction than the buck stopping with HIV-positive prevention. You can't do positive prevention unless you take care of PLHIV, address their viral load or the social and physical environments that help prevent transmission... Positive prevention is about helping PLHIV live full and productive lives and treatment integration helps us do that.

Finally, intervention participants understood integration as a relatively vulnerable development in community-based work, subject to numerous challenges and barriers. These included high staff turnover, the rapidly changing nature of treatment information and the need to prioritize immediate and basic client needs all of which, they reported, make integration difficult:

The entire HIV/AIDS field needs to create a culture where integration is the norm. But it's hard to do when organizations don't have the resources or time to reposition themselves to make those changes, even if they know it's necessary. We just don't have the luxury of time and resources to learn something new.

A final barrier to integration was the tendency for treatment and HIV prevention education to be treated as separate streams by funding agencies. As one intervention participant noted:

One of the challenges is having everyone buy into the importance of integration of all services. I've gotten 
into major disagreements with funders on this. We don't benefit from money from [provincial funding body] to enhance prevention efforts for gay men because in their mind...we are not a [CBAO]. So the mind-shift hasn't happened at the level of funders.

\section{Discussion}

This study contributes findings on how the concept of integration is understood by funders, CATIE organizers and participants of a national capacity-building initiative. This is an important starting place for research on integration initiatives such as CATIE's which are organized around a new concept. Developing a better understanding of differences in how study participants understand integration and learning more about how the concept is understood by community workers can help refine the intervention and better position it to encourage change in how CBAOs connect prevention and treatment information services. Here we explore two central challenges that deserve attention as such efforts move forward.

The first is the challenge of distinguishing a communitybased concept of integration from alternative uses of the term. Our research was conducted during a time when competing versions of integration were being articulated from multiple institutional sites. As CATIE began work on the initiative, the WHO started to advance a notion of integration based in concerns about a false dichotomy between treatment and prevention. ${ }^{3}$ As suggested by our interviews, PHAC also began to develop a version of integration emphasizing HIV prevention concerns related to the increased life expectancy of PLHIV. PHAC funders were also operating with a quite different notion of integration expressed by the Federal Initiative. Rather than emphasizing the need to integrate HIV treatment and prevention, it emphasized the need to link HIV programs with programs related to other infectious diseases such as TB and STIs to which PLHIV can be vulnerable. ${ }^{32}$ Finally, general bureaucratic notions of integration emphasizing efficiency through amalgamation of administrative units circulated widely at this time.

Integration is a key emerging organizing principle of global HIV/AIDS work. It is also a term with multiple meanings. Health promotion research suggests that multiple interpretations of emerging and novel concepts can be a barrier to successful program implementation. ${ }^{33}$ In order for integration to be successfully popularized amongst CBAOs, the concept's meanings and implications for CBAOs will need to be specified against alternative notions that express different priorities.

Our study helps in this process by identifying dimensions of an emerging community-based perspective on integration.
While understandings of integration will vary across CBAOs, reflecting their particular organizational contexts, this study points to key elements that distinguish an overall communitybased based concept of integration. Such a concept is, in the first instance, grounded in the phenomenological universe of front-line service work and a concern for the needs of PLHIV and other clients. It focuses on ways of linking and combining the prevention and treatment-related services of CBAOs and has as its primary rationale, improving the health of clients rather than any a priori concerns with efficiency.

The social determinants of health are a second central feature of a community-based concept of integration. Unlike some proposals for integration which have been critiqued for positioning treatments as a quick fix for HIV transmission, ${ }^{34-35}$ a community-based concept recognizes that HIV risk and transmission and access to prevention and treatment services are shaped by gender, race, sexual orientation, income, and other social determinants of health. A community-based concept of integration thus seeks to link treatment and prevention in ways that connect action on individuals with efforts to intervene at the level of key social, political and economic drivers of health.

Finally, a community-based concept of integration acknowledges the salience of multiple forms of knowledge for health decision making. Research shows that decisions related to HIV treatment and safer sex rely on more than biomedical information and a strict rational perspective. ${ }^{16,36}$ They involve questions of desire, pleasure, fear and anxiety and connect biomedical knowledge with information from experiential, community and media sources. Research on the use of ART to prevent HIV transmission is complex and provisional. It is being disseminated in a context of concerns about lapses in safer sex, increased HIV-related stigma and a widespread trend to criminalize HIV transmission. ${ }^{37}$ As such, a community-based perspective recognizes the need for health education to be delivered at the interface of biomedical ways of knowing and clients' experiential knowledge while also responding to the political context of integration and its link to public issues.

The second challenge is that of addressing tensions associated with the integration of treatment and prevention in a community-based context. Most discussions of integration emphasize the complementarity of treatment and prevention, describing it as a "win-win" situation. ${ }^{1-3,12-13}$ While participants in this study understood integration in ways that emphasized the complementarity of HIV prevention and treatment, they also recognized sources of tension and potential conflict between them. These tensions relate to the historical positioning of treatment and prevention within CBAOs through different forms of reasoning and community mobilization, and siloed funding structures. 
In the Canadian context, treatment information services have been associated with meeting the needs of PLHIV and with grass-roots organizing and advocacy towards that goal. Historically, treatment activism and empowerment focused on the health of PLHIV in contrast to most CBAO work which emphasized the goal of preventing HIV. This historical context explains some community members' concerns that under the call for integration, vulnerable treatment information services may lose out.

Such concerns have been prominent in recent debates about positive prevention - a range of activities that shift the direction of prevention from the "general public" toward PLHIV by actively enlisting them as participants and targets of HIV prevention efforts..$^{38}$ Positive prevention can contribute to integration when, for example, efforts to decrease risk behaviours among PLHIV also improve their health by reducing the risk of co-infections. ${ }^{39}$ However, many PHA-based advocacy groups have argued that this potential of positive prevention has been left unrealized, and instead the predominant "public health control perspective" treats PLHIV as vectors of infection, while underplaying their health and treatment needs. ${ }^{40}$

Traces of this debate can be found in CATIE staff and intervention participants' comments about integration. Our study suggests sources of tension in integration based on the historical relationship between the development of CBAO services and PHA-based social movements. As the intervention and related integration efforts move forward, they must attend to this complexity of history and politics and approach the alignment of prevention and treatment services with care, sensitivity and an explicit commitment to the health of PLHIV.

To conclude, integration is an important, emerging principle of HIV pandemic response. This paper has offered an analysis of conceptualizations of integration, highlighting differences of understanding among funders, organizers and participants in a national initiative that seeks to help CBAOs better link treatment information services with established prevention and education activities. Drawing on the experiences of community participants in the intervention it has identified key elements that distinguish a community-based perspective on integration from alternative uses of the concept.

Varying perspectives and proposals for integration reflecting different priorities and values will be developed as the concept continues to be popularized in the HIV sector. This paper points to elements of a community-based approach worth preserving: a phenomenological grounding in front-line service work, a commitment to the social determinants of health and an approach to health education that addresses multiple forms of knowledge and the political context of integration. It also points to sites of potential tension, including the vulnerability of treatment information services and a public health orientation to PLHIV as sources of infection.

Developing approaches to integration that respond to the health needs of PLHIV while also working to prevent the spread of HIV transmission is an important, if challenging goal for CBAOs. Future research exploring how CBAOs with different histories, resources and target populations have operationalized integration in pursuit of that goal is a worthy endeavour. So too is research exploring understandings of integration among community workers with different organizational positions and histories.

\section{Acknowledgements}

We thank all those who participated in our study. We thank Melanie Rock who provided excellent advice and feedback on earlier versions of this manuscript. The article benefited from the guidance of Associate Editor Louise Potvin and from the helpful comments of the IJPH reviewers. Finally we thank the funders of our research: the Public Health Agency of Canada (6962-15-2005/6510039), the Social Sciences and Humanities Research Council of Canada (410-2005-2003 to E.M.) and the Canadian Institutes of Health Research (New Investigator Award to E.M.).

\section{Sommaire}

Objectif: Cet article a pour but de combler des lacunes concernant la conceptualisation de l'intégration dans les organismes communautaires de lutte contre le sida.

Méthodes: Une évaluation des processus d'une intervention communautaire au plan national a été développée et menée par CATIE (le Réseau canadien d'info-traitements sida) afin d'améliorer la disponibilité d'informations sur les traitements dans les organismes communautaires de lutte contre le sida et de promouvoir leur intégration avec les services de prévention.

Notre étude a consisté en 13 entrevues avec des participants de 6 organismes de lutte contre le sida de partout au Canada, des membres du personnel de CATIE et des commanditaires, ainsi que d'un exercice de vérification impliquant 25 personnes.

Résultats: Pour les participants à l'intervention, la conceptualisation de l'intégration consiste à relier les traitements de première ligne du VIH avec les services de promotion de la santé et de la prévention, à accentuer la médiation entre les connaissances scientifiques et non-spécialisées, le contexte politique d'intégration et le rôle joué par les facteurs sociaux en ce qui 
concerne la santé et l'accès aux services des clients. Les défis posés par l'intégration comprennent, entre autres, le haut roulement de personnel et la rigidité des structures de financement. Les aspects complexes de l'éducation de la santé concernant la relation entre la charge virale et la transmission du VIH est un domaine crucial de la prestation de services intégrés.
Conclusion: Les résultats de l'étude permettent de faire une distinction entre le concept de l'intégration selon les organismes communautaires et d'autres usages du terme, tout en signalant les principales difficultés associées aux efforts d'intégration de la prévention et du traitement du VIH dans un contexte communautaire.

\section{References}

1. Salomon JA, Hogan DR, Stover J, et al. Integrating HIV prevention and treatment: from slogans to impact. PLoS Med 2005;2:16

2. Simao M, Deschamps M, Kavi A, et al. Getting the balance right: integrating HIV prevention and treatment programming. A panel discussion. XVI International AIDS Conference in Toronto, Canada, 14 August 2006.

3. Schwartländer B, Grubb I, Perriëns J. The 10-year struggle to provide antiretroviral treatment to people with HIV in the developing world. Lancet 2006;368:541-6.

4. HIV prevention in the era of expanded treatment access. Global HIV Prevention Working Group, 2004. (Accessed August, 01, 2007 at http://www.globalhivprevention.org/reports.html).

5. WHO/UNAIDS. Progress on global access to HIV antiretroviral therapy: An update. Geneva: World Health Organization, 2005.

6. Gayle HD. Expanding access to HIV prevention. AIDS Res Ther 2006;3:2.

7. Castilla J, del Romero J, Hernando V, Marincovich B, García S, Rodríguez C. Effectiveness of highly active antiretroviral therapy in reducing heterosexual transmission of HIV. J Acq Immun Def Synd 2005;40:96-101.

8. Cohen MS, Gay C, Kashuba ADM, Blower S, Paxton L. Narrative review: antiretroviral therapy to prevent the sexual transmission of HIV-1. Ann Intern Med 2007;146:591-601.

9. Vernazza P, Hirschel B, Bernasconi E, et al. Les personnes séropositives ne souffrant d'aucune autre MST et suivant un traitement antiretroviral efficace ne transmettent pas le VIH par voie sexuelle. Bulletin des médecins suisses 2008;89:165-9.

10. Montaner J, Hogg R, Wood E, et al. The case for expanding access to highly active antiretroviral therapy to curb the growth of the HIV epidemic. Lancet 2006;368:531-6.

11. Abbas UL, Anderson RM, Mellors JW. Potential impact of antiretroviral therapy on HIV-1 transmission and AIDS mortality in resource-limited settings. J Acq Immun Def Synd 2006;41:632-41.
12. Koenig SP, Léandre F, Farmer P. Scaling-up HIV treatment programmes in resource-limited settings: the rural Haiti experience. AIDS 2004; 18:S21-S25.

13. Mukherjee JS, Eustache FE. Community healthworkers as a cornerstone for integrating HIV and primary healthcare. AIDS Care 2007; 19:S73-S82.

14. Veinot TC. The case for an integrated approach to HIV/AIDS prevention, support and treatment services in Canada. J HIV/AIDS Soc Serv 2006;5:181-99.

15. Chillag K, Bartholow K, Cordeiro J, et al. Factors affecting the delivery of HIV/AIDS prevention programs by community-based organizations. AIDS Educ Prev 2002;14:27-37.

16. Mykhalovskiy, E. Beyond decision making: class, community organizations, and the healthwork of people living with HIV/AIDS. Contributions from institutional ethnographic research. Medical Anthropology 2008;27:136-63.

17. About CATIE. Toronto: Canadian AIDS Treatment Information Exchange, 2008. (Accessed May, 04, 2008 at http://www.catie.ca/eng/ AboutCATIE/AboutCATIEIndex.shtml).

18. Edmiston L, Stanley C, Rogers T. HIV treatment information: who does what and how? A survey of ASOs across Canada. Can J Infect Dis Med Microbiol 2006;17(Supplement SA).

19. Minkler M, Wallerstein N. Community-based participatory research for health. San Francisco: Jossey-Bass, 2003.

20. Mykhalovskiy E, McCoy L. Troubling ruling discourses of health: using Institutional Ethnography in community-based research. Crit Pub Hlth 2002;12:17-37.

21. Israel BA, Eng E, Schultz AJ, Parker EA. Methods in community-based participatory research for health. San Francisco: Jossey-Bass, 2005.

22. Kinsman J, Kamali A, Kayesigye E, et al. Quantitative process evaluation of a communitybased HIV/AIDS behavioural intervention in rural Uganda. Health Educ Res 2002;17:253-65.
23. Ahmed N, Flisher AJ, Mathews C, Jansen S, Mukoma W, Schaalma H. Process evaluation of the teacher training for an AIDS prevention programme. Health Educ Res 2006;21:621-32.

24. Deming WE. Out of the crisis. Cambridge, MA: MIT Press, 1986.

25. House ER. The role of the evaluator in a political world. Can J Prog Eval 2004;19:1-16.

26. CPHA. Leading together: Canada takes action on HIV/AIDS (2005-2010). Ottawa: Canadian Public Health Association, 2005.

27. United Nations. Declaration of Commitment on HIV/AIDS. A/RES/S-26/2. New York: United Nations, 2001

28. Centers for Disease Control and Prevention. Incorporating HIV prevention into the medical care of persons living with HIV: recommendations of CDC, the Health Resources and Services Administration, the National Institutes of Health, and the HIV Medicine Association of the Infectious Diseases Society of America. MMWR 2003;52:1-24.

29. Mykhalovskiy E, Smith GW. Getting 'hooked up': a report on the barriers people Living with HIV/AIDS face accessing social services. Toronto: Ontario Institute for Studies in Education,1994.

30. DeVault ML, McCoy L. Institutional ethnography: using interviews to investigate ruling relations. In: Gubrium JF, Holstein JA, eds. Handbook of interview research: context and methods. Thousand Oaks: Sage Publications, 2001:751-76.

31. Atkinson P. The ethnographic imagination: textual constructions of reality. London: Routledge, 1990.

32. Public Health Agency of Canada. Federal initiative to address HIV/AIDS in Canada, 2007. (Accessed October, 15, 2008 at http://www.phacaspc.gc.ca/aids-sida/fi-if/index-eng.php).

33. Ritchie D, Parry O, Gnich W, Platt S. Issues of participation, ownership and empowerment in a community development programme: tackling smoking in a low-income area in Scotland. Health Promot Int 2004;19:51-9. 
Conceptualizing the integration of HIV treatment and prevention: findings from a process evaluation of a community-based,

national capacity-building intervention
34. Paxton LA, Hope T, Jaffe H. Pre-exposure prophylaxis for HIV infection: what if it works? Lancet 2007;370:89-93.

35. Imrie J, Elford J, Kippax S, Hart GJ. Biomedical prevention - and social science. Lancet 2007;370:10-1

36. Adam B. Infectious behaviour: imputing subjectivity to HIV transmission. Soc Theory Health 2006;4:168-79.

37. Burris, $S$, Cameron, E. The case against criminalization of HIV transmission. JAMA 2008;300:578-80.
38. Kalichman SC, ed. Positive prevention: reducing HIV transmission among people living with HIV/AIDS. New York: Springer, 2005.

39. Wolitski RJ, Janssen RS, Onorato IM, Purcell DW, Crepaz N. An overview of prevention with people living with HIV. In: Kalichman SC, ed. Positive prevention: reducing HIV transmission among people living with HIV/AIDS. New York: Springer, 2005:1-28.

40. Moody K. Positive prevention: opportunity or threat, 2007. (Accessed January, 05, 2008 at http://www.healthdev.org/eforums/cms/ Prevention). individual.asp?sid=183\&sname=Accelerating
Int J Public Health 54 (2009) 133-141

(C) Birkhäuser Verlag, Basel, 2009
Address for correspondence

Eric Mykhalovskiy, Associate Professor

Department of Sociology,

York University

4700 Keele St. Toronto, ON, M3J 1P3

Canada

E-mail: ericm@yorku.ca 